\title{
Erratum to: Influence of gender on pacing adopted by elite triathletes during a competition
}

\author{
Yann Le Meur · Christophe Hausswirth • \\ Sylvain Dorel · Frank Bignet · Jeanick Brisswalter • \\ Thierry Bernard
}

Published online: 12 March 2011

(C) Springer-Verlag 2011

\section{Erratum to: Eur J Appl Physiol (2009) 106:535-545 DOI 10.1007/s00421-009-1043-4}

Twelve elite triathletes were evaluated during this study performed during the 2007 Beijing Triathlon World Cup (China). For methodological reasons, three of them were excluded from a part of the analysis. Particular measurements were also conducted for these three triathletes. The aim of the present corrigendum is to correct the manuscript accordingly.

Page 536, paragraph 4: Subjects

Lines 1-5. Original text: "Twelve triathletes (6 women, 6 men) from the French and Swiss national triathlon teams participated in this study. They were familiar with all testing procedures and gave their informed written consent to take part to this study that was conducted according to the Declaration of Helsinki."

Corrected text: "Nine triathletes ( 3 women, 6 men) from the French national triathlon team participated in this study. They were familiar with all testing procedures and

The online version of the original article can be found under doi:10.1007/s00421-009-1043-4.

\footnotetext{
Y. Le Meur · C. Hausswirth $(\varangle) \cdot$ S. Dorel

Research Department, National Institute of Sport and Physical

Education (INSEP), Paris, France

e-mail: christophe.hausswirth@insep.fr

Y. Le Meur · J. Brisswalter · T. Bernard

Handibio, EA 4322, University of South Toulon-Var,

La Garde Cedex, France

F. Bignet

French Federation of Triathlon, La Plaine Saint Denis, France
}

gave their informed written consent to take part in this study that was conducted according to the Declaration of Helsinki. Three female elite triathletes agreed to complete this group after being informed of the purpose of the study. Their data were transmitted by their national head coach due to his federal attributions."

Page 536, paragraph 5: Pre-race maximal testing

Lines 1-4. Original text: "Two weeks before the competition, each subject performed a maximal test in swimming, cycling and running in a randomized order. These tests were separated by a 48 -h rest period."

Corrected text: "Nine subjects ( 3 females, 6 males) performed a maximal test in swimming, cycling and running in a randomized order. These tests were separated by a 48-h rest period. The three females, who did not complete these tests, were excluded from the subsequent physiological analyses (i.e. heart rate and power output distribution values)."

Page 536: Table 1

Corrected version of Table 1 is given here:

Table 1 Anthropometrical and physiological characteristics of the triathletes (females, $n=3$; males, $n=6$ )

\begin{tabular}{lcc}
\hline Parameters & Women & Men \\
\hline Age (years) & $28 \pm 3$ & $30 \pm 6$ \\
Weight $(\mathrm{kg})$ & $56 \pm 5$ & $67 \pm 5$ \\
Height $(\mathrm{cm})$ & $166 \pm 5$ & $180 \pm 3$ \\
$\dot{V} \mathrm{O}_{2 \max }\left(\mathrm{mlO}_{2} \mathrm{~min}^{-1} \mathrm{~kg}^{-1}\right)$ & $60.9 \pm 7.0$ & $71.7 \pm 5.4$ \\
$\operatorname{MAP}(\mathrm{W})$ & $286 \pm 11$ & $418 \pm 22$ \\
\hline
\end{tabular}


Table 1 continued

\begin{tabular}{lcc}
\hline Parameters & Women & \multicolumn{1}{l}{ Men } \\
\hline MAP/weight $\left(\mathrm{W} \mathrm{kg}^{-1}\right)$ & $5.2 \pm 0.3$ & $6.2 \pm 0.2$ \\
$\mathrm{P}_{\mathrm{VT} 1}(\mathrm{~W})$ & $199 \pm 14$ & $264 \pm 20$ \\
$\mathrm{P}_{\mathrm{VT} 1}(\% \mathrm{MAP})$ & $69.6 \pm 3.5$ & $63.2 \pm 4.8$ \\
$\mathrm{P}_{\mathrm{VT} 2}(\mathrm{~W})$ & $243 \pm 5$ & $349 \pm 22$ \\
$\mathrm{P}_{\mathrm{VT} 2}$ (\%MAP) & $85.0 \pm 3.2$ & $83.5 \pm 5.3$ \\
\hline
\end{tabular}

$\dot{V} O_{2 \max }$ maximal oxygen uptake, MAP maximal aerobic power, $P_{V T I}$ power output at the first ventilatory threshold, $P_{V T 2}$ power output at the second ventilatory threshold

Page 537, paragraph 7: Speed measurements

Lines 1-3. Original text: "Running phase Running velocity was continuously recorded using a $\mathrm{s} 3$ accelerometer (Polar RS800sd, Kempele, Finland)."

Corrected text: "Running phase For the nine triathletes, running velocity was continuously recorded using a s3 accelerometer (Polar RS800sd, Kempele, Finland)."

Line 18. Original text: "were recorded at the sampling rate of $1 \mathrm{~Hz} . "$

Corrected text: "were recorded at the sampling rate of $1 \mathrm{~Hz}$. At the same time, running speed was measured in the 12 triathletes using the synchronized video analysis system employed for the determination of running ranking (see Page 538, para 1). This system included five digital cameras located at the beginning of the run (i.e. exit of bike transition: $0 \mathrm{~m}$ ), 283, 937, 1,272 and 1,829 $\mathrm{m}$ (i.e. changes of slope). Distances between these points were measured using both a measuring wheel (Debrunner, Givisiez, art. 851.236) and the same global positioning system used for swimming (GPS, Garmin GPSRAP 60CSx, Garmin Europe, UK). Mean running speed (in $\mathrm{km} \mathrm{h}^{-1}$ ) of the 12 triathletes considered in the present study on each portion described above was then determined via a subsequent video analysis (Pro suite version 5.0, Dartfish ${ }^{\circledR}$, Fribourg, Switzerland). This method also allowed verification that the data collected with the accelerometer systems (i.e. s3 sensor) for the nine French subjects were accurate and not affected by possible electromagnetic interferences generated by the official timing system."

Page 538, paragraph 4: Heart rate recordings

Lines 1-3. Original text: "Subjects were equipped with a Polar unit (Team system, Kempele, Finland) to record HR throughout the swim, cycle and run phases of the triathlon."

Corrected text: "The nine triathletes, who performed the maximal swimming test, were equipped with a Polar Team
System, Kempele, Finland) to record HR throughout the swim, cycle and run phases of the triathlon."

\section{Page 539: Legend to Figure 1}

Lines 1-2. Original text: "Evolution of mean ( \pm SD) $\left(\% \mathrm{HR}_{\max }\right)$ throughout the race for women and men."

Corrected text: "Evolution of mean $( \pm \mathrm{SD})\left(\% \mathrm{HR}_{\max }\right)$ throughout the race for women $(n=3)$ and men $(n=6)$."

Page 539: Figure 3 and legend

Corrected version of Fig. 3 and its legend is given here:

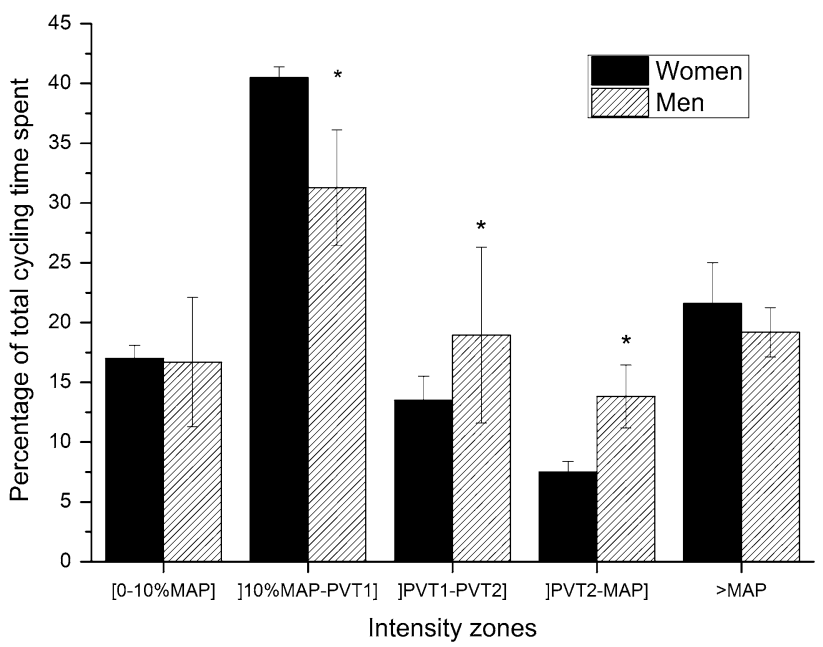

Fig. 3 Distribution of exercise time spent in intensity zones: below $10 \%$ of maximal aerobic power (zone 1), above $10 \%$ of maximal aerobic power and below power output at first ventilatory threshold $\left(<\mathrm{P}_{\mathrm{VT} 1}=64.9 \pm 3.9 \%\right.$ MAP; zone 2$)$, above $\mathrm{P}_{\mathrm{VT} 1}$ and below power output at second ventilatory threshold $\left(<\mathrm{P}_{\mathrm{VT} 2}=82.3 \pm 3.3 \% \mathrm{MAP}\right.$; zone 3), above $\mathrm{P}_{\mathrm{VT} 2}$ and below $100 \%$ of maximal aerobic power $(<100 \%$ MAP; zone 4$)$ and above $100 \%$ of maximal aerobic power $(>100 \%$ MAP; zone 5). Females, $n=3$; males, $n=6$. * Significantly different from women $(P<0.05)$

Page 540, paragraph 7: Discussion

Lines 15-16. Original text: “(4) no effect of gender was observed on the relative intensities reached during the overall phases."

Corrected text: "(4) no effect of gender was observed on the relative cycling time spent above MAP."

Page 541, paragraph 5: Discussion

Lines 1-15. Original text: "A strong likeness between women and men in the global distribution of the time spent in the five zones of intensity was observed. This resemblance suggested that women do not try more than men to 
save energy during the cycle leg for the subsequent run. This finding questions the results of Vleck et al. (2008) who suggested that females did not particularly tend to "bridge gaps" in the cycling section during the Lausanne 2002 ITU WC. The authors described a decrease in cycling speeds for all female bike packs. In contrast males at the rear packs tended to push the pace in order to "catch up to" the leading athletes. According to these authors (Vleck et al. 2008), anecdotal evidence (personal communications) suggested that this pacing is characteristic of elite females but they could not know whether it is deliberate or reflects fatigue."

Corrected text: "A similar distribution of the time spent in the supramaximal intensity zone (zone 5) was observed for both genders. This resemblance suggested the necessity for both genders to increase their maximal aerobic power to limit the potential deleterious effects of the time spent in this intensity zone during international triathlon competitions. Further investigations are required to confirm this likeness." 